\title{
Age-dependent vitreous separation from the macula in a clinic population
}

\author{
This article was published in the following Dove Press journal: \\ Clinical Ophthalmology \\ 7 July 2016 \\ Number of times this article has been viewed
}

\author{
Zahid Syed' \\ Michael W Stewart ${ }^{2}$ \\ 'Georgetown University, Washington, \\ DC, ${ }^{2}$ Department of Ophthalmology, \\ Mayo School of Medicine, Jacksonville, \\ FL, USA
}

Background: Vitreous degeneration begins soon after birth and accelerates throughout life. Vitreous liquefaction with a slowly progressive separation of the posterior hyaloid from the peripheral macula usually leads to complete posterior vitreous detachment. The purpose of this study is to measure the age-related prevalence of partial vitreous separation and the length of residual vitreous adhesion in an ophthalmology clinic population.

Methods: Patients examined by the senior author (MWS) during a 6-month period were included in a retrospective chart review. Demographic data and spectral domain optical coherence tomography scan results were gathered. Data analysis with descriptive statistics focused on the prevalence and extent of partial vitreous separation.

Results: The mean age of the study patients was 69.9 years, and $62 \%$ were phakic. The highest prevalence of partial posterior hyaloid separation from the internal limiting membrane $(71.2 \%)$ was seen in the 50- to 54-year age group. This prevalence rate steadily decreased to $5.6 \%$ in the 95- to 99-year age group. The prevalence of complete vitreous detachment as determined by slit-lamp biomicroscopy increased from $1.7 \%$ in the $<50$-year age group to a maximum of $29.2 \%$ in the 75 - to 79 -year group. The length of vitreomacular adhesion averaged $4.6 \mathrm{~mm}$ in the 50- to 54-year age group and steadily decreased to $2.1 \mathrm{~mm}$ in the 90 - to 95 -year group.

Conclusion: Vitreomacular separation affects the majority of eyes in the sixth decade of life. The prevalence of partial vitreous separation decreases with advancing age, probably because an increasing number of these patients progress to complete posterior vitreous detachment.

Keywords: optical coherence tomography, posterior hyaloid, posterior vitreous detachment, syneresis, vitreomacular adhesion, vitreous degeneration

\section{Introduction}

The vitreous humor (volume of $\sim 4 \mathrm{~mL}$ in an adult) comprises the majority of the eye's volume $^{1}$ and is responsible for several visually debilitating conditions such as retinal tear and detachment, macular hole, macular pucker, and vitreomacular traction (VMT). The vitreous has a uniform gel-like consistency at birth, but liquefaction begins soon thereafter, with pockets of aqueous fluid appearing by the age of 4 years. ${ }^{2}$ As aging continues, the loss of type IX collagen increases the surface area on sticky type II collagen fibrils and allows them to fuse when they come into contact. ${ }^{3,4}$ Collagen aggregation promotes vitreous liquefaction, resulting in pockets of aqueous fluid, most of which are situated within the central vitreous, while others lie adjacent to the posterior hyaloid membrane. The collagen fibers that attach the posterior hyaloid surface to the internal limiting membrane (ILM) also slowly degenerate with advancing age. ${ }^{5}$

Twenty percent of the vitreous is liquefied by the age of 18 years and $50 \%$ by the age of 80-90 years. ${ }^{6}$ Vitreous liquefaction, together with weakening of the adhesion between the posterior hyaloid and the ILM, promotes posterior vitreous detachment (PVD). ${ }^{5}$
Correspondence: Michael W Stewart Department of Ophthalmology, Mayo School of Medicine, 4500 San Pablo Road, Jacksonville, FL 32224, USA

Tel + I 9049532232

Fax + I 9049537040

Email stewart.michael@mayo.edu
Clinical Ophthalmology 2016:10 I237-1243

1237

Dovepress f in 0

http://dx.doi.org/10.214710PTH S99635 (c) (1) (-) 2016 Syed and Stewart. This work is published and licensed by Dove Medical Press Limited. The full terms of this license are available at https://www.dovepress.com/terms.php (c) hereby accept the Terms. Non-commercial uses of the work are permitted without any further permission from Dove Medical Press Limited, provided the work is properly attributed. For permission for commercial use of this work, please see paragraphs 4.2 and 5 of our Terms (https://www.dovepress.com/terms.php). 
Investigators using funduscopic evaluations reported that the prevalence of PVD was 50\% in patients over the age of 50 years and $65 \%$ in patients over the age of 65 years. ${ }^{7}$ Subsequent histologic analyses challenged the validity of these findings ${ }^{8}$ and called into question the accuracy of funduscopic examination because many eyes diagnosed with PVD actually had vitreous schisis with preretinal bursae that had been mistaken for posterior hyaloid separation. ${ }^{9}$

The introduction of optical coherence tomography (OCT) has given us a deeper understanding of vitreoretinal interface (VRI) abnormalities. Spectral domain optical coherence tomography (SD-OCT) accurately visualizes the VRI with an axial resolution of 3-6 $\mu \mathrm{m}$. High-resolution, cross-sectional images show that vitreous detachment is a gradual, stepwise process that begins in the peripheral macula. This slowly extends posteriorly to involve the fovea and often culminates with sudden, complete release from the fovea and disc, thereby clinically presenting as a PVD. ${ }^{2}$

The extent of shallow detachment between the posterior hyaloid and the central $6 \mathrm{~mm}$ of the retina's ILM can be accurately measured with SD-OCT. The limitations of OCT imaging become apparent, however, when we attempt to distinguish complete PVD, where the separated posterior hyaloid often lies $>2 \mathrm{~mm}$ above the ILM and is outside the range of the OCT image, from no detachment. ${ }^{10}$ In these eyes, clinical examination of the vitreous together with B-scan ultrasound is necessary to diagnose a complete PVD. ${ }^{11}$

The prevalence of PVD increases with age, but the extent of partial vitreous separation in different age groups is still under investigation. ${ }^{12,13}$ This issue becomes clinically important because a partially detached vitreous can exert traction on the ILM and cause ILM damage that leads to macular pucker and macular hole. VMT alters the severity of chorioretinal vascular conditions such as diabetic macular edema ${ }^{14,15}$ and neovascular age-related macular degeneration ${ }^{16-19}$ and limits the effectiveness of pharmacologic treatment with drugs that inhibit vascular endothelial growth factor. ${ }^{20}$ Pharmacotherapy to hasten vitreomacular separation had been developed to treat symptomatic VMT. The intravitreal injection of ocriplasmin (Jetrea $^{\circledR}$; ThromboGenics, Leuven, Belgium) cleaves remaining vitreoretinal adhesions and restores macular anatomy and function in some symptomatic eyes. ${ }^{21}$

The present study was conducted to determine the prevalence of vitreomacular adhesion (VMA) in a large clinic population.

\section{Methods}

This retrospective chart review was approved by the Mayo Clinic Institutional Review Board. For this retrospective study, the Mayo Clinic Institutional Review Board did not require patient consent. All data was de-identified. All patients examined by one of the authors (MWS) between January 1, 2013 and June 30, 2013, were identified from the electronic scheduling calendar, and data from the electronic medical record were evaluated for the study. Exclusion criteria included previous pars plana vitrectomy, high myopia $(>6 \mathrm{D})$, history of uveitis, and unavailability of evaluable OCT images. Patients who were evaluated more than once during the study period were counted only once for the overall VMA.

\section{Patient identification and clinical data}

Demographic information on each patient was obtained from the medical record and tabulated for analysis. Identified clinical data included the following: best-corrected visual acuity; intraocular pressure; slit-lamp examination of the anterior segment; lens status (phakic, aphakic, pseudophakic) including the location of any intraocular lens (anterior or posterior chamber); biomicroscopic examination of the vitreous optic disc, macula, and retinal vessels; and indirect ophthalmoscopic examination of the peripheral retina.

The vitreous was examined with slit-lamp biomicroscopy using a 78 or $90 \mathrm{D}$ handheld condensing lens. The vitreous was characterized as either completely detached or attached, based on the presence or absence of a partial or complete Weiss ring. The biomicroscopic status of the vitreous was correlated with the results of the OCT scan, and inconsistencies, though rare, were reconciled by the investigators.

\section{Optical coherence tomography}

Throughout the study period, all patients not previously seen in the Department of Ophthalmology by one of the authors (MWS) within the previous 6 months were routinely evaluated with SD-OCT (Cirrus ${ }^{\circledR}$; Carl Zeiss Meditec AG, Jena, Germany). For patients seen more than once during the study period, usually at least one set of scans were performed with additional scans performed at the discretion of the investigator, based upon the patients' diagnoses and need for treatments. Standard scanning protocols of both the macula and nerve fiber layer were performed.

Six-millimeter macular cube scans were used for evaluating patients. The state of the posterior hyaloid membrane on OCT was characterized by the presence or absence of separation from the ILM in any part of the horizontal foveal scan or vertical construct. Any observed separation of the vitreous from the ILM, either partial or complete, resulted in a characterization of partial vitreous separation or incomplete PVD. If the vitreous appeared to be completely separated from the ILM throughout the scan, an observation of Weiss 
ring on the biomicroscopic exam was required before the eye could be characterized as having a complete PVD. Eyes with no vitreoretinal separation observed on OCT were characterized as having either complete PVD or completely attached vitreous, depending upon the biomicroscopic examination. B-scan ultrasonography was not part of the routine examination of these eyes.

The length of vitreoretinal separation on OCT in each eye was measured with electronic calipers. The lengths of vitreomacular separation on the horizontal scan and vertical construct were averaged to determine a single number. Because the strength of the VMA varies among common retinal conditions, and the degree of adhesion can affect disease severity and response to therapy, separate calculations were performed on eyes with age-related macular degeneration (which did not undergo intravitreal injections) and diabetic retinopathy (without previous laser photocoagulation), and eyes without retinal abnormalities.

Descriptive statistics, including mean and standard deviation, were calculated with Excel Microsoft Office 2013 software.

\section{Results \\ Demographic data}

Baseline demographic data can be seen in Table 1. During the study period, evaluable data were collected on 1,436 unique patients. The mean age of the cohort was 69.9 years (standard deviation: 14.7) with $29.8 \%$ of patients under the age of 65 years. Mean intraocular pressures in the right and

Table I Demographic data of study population

\begin{tabular}{ll}
\hline Characteristic & Data \\
\hline Subjects, $\mathrm{n}$ & $\mathrm{I}, 436$ \\
Age, mean \pm SD (years) & $69.9 \pm \mid 4.7$ \\
Age distribution by years, $\mathrm{n}(\%)$ & \\
$<50$ & $120(8.4)$ \\
$50-55$ & $66(4.6)$ \\
$55-60$ & $108(7.5)$ \\
$60-65$ & $133(9.3)$ \\
$65-70$ & $190(13.2)$ \\
$70-75$ & $230(16.0)$ \\
$75-80$ & $192(13.4)$ \\
$80-85$ & $189(13.2)$ \\
$85+$ & $208(14.5)$ \\
Lens status, $\mathrm{n}(\%)$ & \\
Phakic & $1,780(62.0)$ \\
Pseudophakic & $1,074(37.4)$ \\
Aphakic & $18(0.6)$ \\
Intraocular pressure, mean \pm SD $(\mathrm{mmHg})$ & \\
OD & $14.95 \pm 3.44$ \\
OS & $14.99 \pm 3.5 \mathrm{I}$ \\
\hline
\end{tabular}

Note: More than half of the cohort is 70 years of age or older.

Abbreviations: OD, right eye; OS, left eye; SD, standard deviation. left eyes were 14.95 and $14.99 \mathrm{mmHg}$, respectively. Lens status reflected the age distribution of the population with $62.0 \%$ of eyes being phakic, $37.4 \%$ pseudophakic, and $0.6 \%$ aphakic.

\section{Vitreous status}

The status of the vitreous - attached, partial separation, and complete detachment - is summarized by 5 -year increments in Table 2. The prevalence of partial vitreous separation below the age of 50 years was $61.7 \%$, and it peaked at $71.2 \%$ in the first analyzed 5-year interval (50-54 years). The prevalence of partial PVD then decreased steadily through each 5-year interval until reaching $5.6 \%$ in the 95 - to 99 -year group.

The prevalence of no vitreous separation, calculated by the formula: (all eyes - partial separation-PVD by biomicroscopy)/ all eyes, was $36.7 \%$ in the < 50 -year group, dropped to $20.3 \%$ in the 60 - to 64 -year group, and then steadily rose to $65.6 \%$ in the 85- to 89-year group, after which it remained at or $>50 \%$.

The prevalence of complete PVD (determined by biomicroscopy) rose from a low of $1.7 \%$ in the $<50$-year group, to a high of $29.2 \%$ in the 75 - to 79 -year group, after which it decreased but remained $>22 \%$.

For all eyes with partial separation of the vitreous, the average length of vitreous attachment to the macula is listed by age groups in Figures 1 and 2 . The length of vitreous attachment decreased from a high of $4.6 \mathrm{~mm}$ in the $<50$-year age group to $2.4 \mathrm{~mm}$ in the 95 - to 99 -age group. A trend-line (calculated by linear regression) is shown in Figure 2. This shows that the average length of VMA decreases by an average of $0.045 \mathrm{~mm}$ per year after the age of 50 years.

\section{Special subgroups}

Patients with normal retinas, macular degeneration, and diabetic retinopathy were evaluated for partial vitreoretinal separation (Figure 3). Patients with macular degeneration resembled those with normal retinas, but there was a nonstatistically significant trend for greater vitreoretinal adhesion in patients with diabetic retinopathy.

\section{Discussion}

Few studies have documented the age-dependent separation of the posterior hyaloid from the ILM of the retina. ${ }^{12,13}$ Our study evaluated a large group of patients, but it was neither randomized nor does it represent the general population. Our cohort excluded patients below the age of 14 years (because of the practice composition), so the pediatric population, a demographic in whom the vitreous is usually completely attached, is underrepresented. The population served by the author's practice has a large number of 
Table 2 Vitreomacular attachment status by 5 -year intervals

\begin{tabular}{|c|c|}
\hline Vitreous status & $\begin{array}{l}\text { Prevalence of } \\
\text { status, n (\%) }\end{array}$ \\
\hline \multicolumn{2}{|l|}{ Overall } \\
\hline No vitreous separation & $596(4 \mid .5)$ \\
\hline Partial vitreous separation & $554(38.6)$ \\
\hline Complete posterior vitreous detachment & $286(19.9)$ \\
\hline \multicolumn{2}{|l|}{ By age interval (years) } \\
\hline \multicolumn{2}{|l|}{$<50$} \\
\hline No vitreous separation & $44(36.7)$ \\
\hline Partial vitreous separation & $74(61.7)$ \\
\hline Complete posterior vitreous detachment & $2(1.7)$ \\
\hline \multicolumn{2}{|l|}{$50-54$} \\
\hline No vitreous separation & $18(27.3)$ \\
\hline Partial vitreous separation & 47 (7I.2) \\
\hline Complete posterior vitreous detachment & $\mathrm{I}(\mathrm{I} .5)$ \\
\hline \multicolumn{2}{|l|}{$55-59$} \\
\hline No vitreous separation & $31(28.7)$ \\
\hline Partial vitreous separation & $65(60.2)$ \\
\hline Complete posterior vitreous detachment & $12(11.1)$ \\
\hline \multicolumn{2}{|l|}{$60-64$} \\
\hline No vitreous separation & $27(20.3)$ \\
\hline Partial vitreous separation & $80(60.2)$ \\
\hline Complete posterior vitreous detachment & $26(19.5)$ \\
\hline \multicolumn{2}{|l|}{$65-69$} \\
\hline No vitreous separation & $62(32.6)$ \\
\hline Partial vitreous separation & $85(44.7)$ \\
\hline Complete posterior vitreous detachment & $43(22.6)$ \\
\hline \multicolumn{2}{|l|}{$70-74$} \\
\hline No vitreous separation & $92(40)$ \\
\hline Partial vitreous separation & $86(37.4)$ \\
\hline Complete posterior vitreous detachment & $52(22.6)$ \\
\hline \multicolumn{2}{|l|}{$75-79$} \\
\hline No vitreous separation & $85(44.3)$ \\
\hline Partial vitreous separation & $51(26.6)$ \\
\hline Complete posterior vitreous detachment & $56(29.2)$ \\
\hline \multicolumn{2}{|l|}{$80-84$} \\
\hline No vitreous separation & $104(55.0)$ \\
\hline Partial vitreous separation & $42(22.2)$ \\
\hline Complete posterior vitreous detachment & $43(22.8)$ \\
\hline \multicolumn{2}{|l|}{$85-89$} \\
\hline No vitreous separation & $84(65.6)$ \\
\hline Partial vitreous separation & $15(11.7)$ \\
\hline Complete posterior vitreous detachment & $29(22.7)$ \\
\hline \multicolumn{2}{|l|}{$90-94$} \\
\hline No vitreous separation & $40(64.5)$ \\
\hline Partial vitreous separation & $8(12.9)$ \\
\hline Complete posterior vitreous detachment & $14(22.6)$ \\
\hline \multicolumn{2}{|l|}{$95-99$} \\
\hline No vitreous separation & $9(50.0)$ \\
\hline Partial vitreous separation & $I(5.6)$ \\
\hline Complete posterior vitreous detachment & $8(44.4)$ \\
\hline
\end{tabular}

Notes: This table shows the status of the vitreous - no vitreous separation, partially vitreous separation, and complete posterior vitreous detachment - by 5-year intervals. After peaking in the 50- to 54-year group, the prevalence of partial vitreous separation declines steadily thereafter. The prevalence of complete posterior vitreous detachment peaks in the late eighth decade and declines slightly thereafter. The decline likely reflects incomplete identification of complete detachment in the oldest age groups.

retirees, so even though ophthalmology clinics generally see more elderly than young patients, this cohort probably includes a disproportionate number of patients over the age of 65 years. Finally, the author's subspecialty practice includes

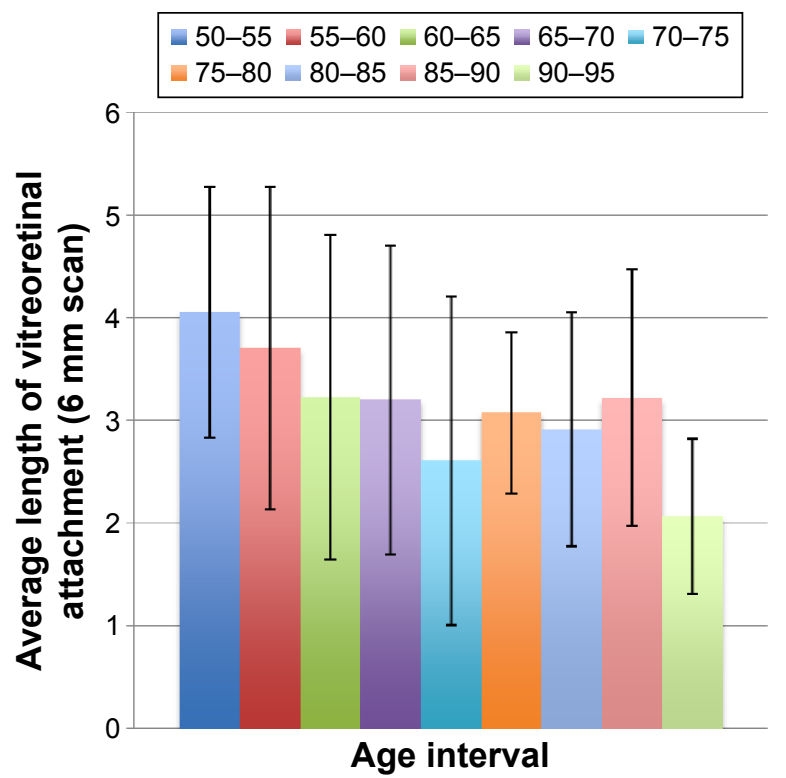

Figure I The average length of vitreomacular adhesion in eyes with partial vitreous separation.

Note: The length of attachment is declining with advancing age.

patients with vitreoretinal conditions such as age-related macular degeneration, diabetic retinopathy, and epiretinal membranes. This cohort, therefore, is biased toward conditions with retinal pathologies.

Our study showed a remarkably high (71.2\%) prevalence of partial vitreous separation in the 50- to 54-year group. This decreased steadily through successive age groups, consistent with the notion that the vitreous completely separates at an increasing rate in populations over the age of 50 years. The proportion of patients in our study with partial vitreous separation differs from that reported by Itakura and Kishi. ${ }^{13}$ For patients in each of the 50- to 59-, 60- to 69-, 70- to 79-, and 80- to 89-year age groups, our proportions with partial vitreous separation were considerably higher than theirs $(64.4 \%$ vs $40 \%, 51.1 \%$ vs $30 \%$,

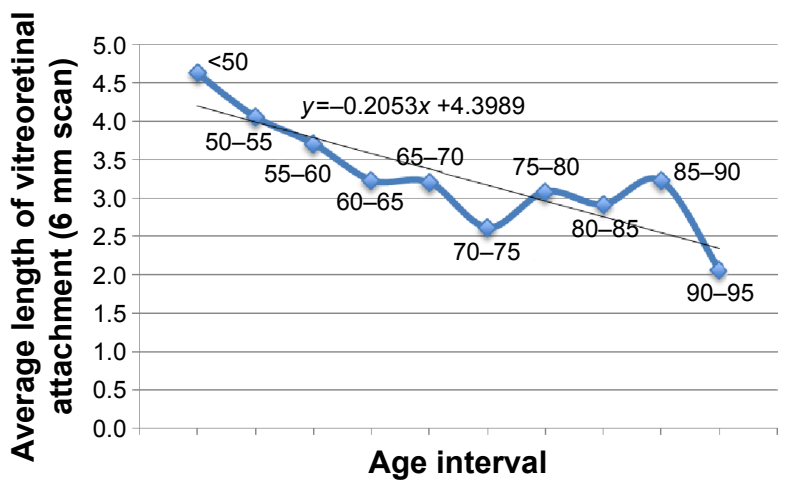

Figure 2 Average length of partial vitreoretinal attachment by age.

Note: The overall lengths of adhesion per 5-year intervals are plotted, and a regression-based trend-line has been added. 


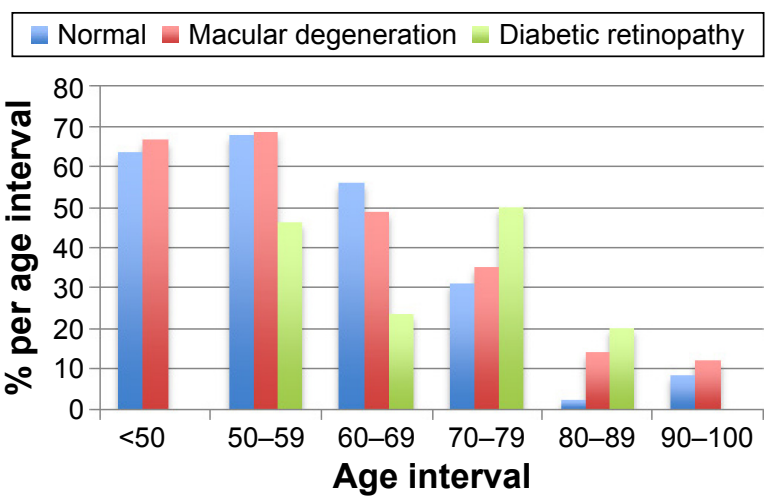

Figure 3 Proportion of normal, macular degeneration, and diabetic retinopathy eyes with partial vitreoretinal separation.

Notes: Lengths of vitreomacular adhesion for patients without retinopathy (nor$\mathrm{mal})$, those with macular degeneration, and those with diabetic retinopathy are plotted. A slight trend toward greater vitreomacular adhesion in elderly patients with diabetic retinopathy is noted.

$32.5 \%$ vs $10 \%, 18.0 \%$ vs $2 \%$ ). The reasons for these differences are unclear but may include the racial compositions of the cohorts, the health of the cohorts (clinic population vs healthy volunteers, general ophthalmology/vitreoretinal practice vs healthy volunteers), and the sizes of the cohorts (1,436 vs 368$)$. Itakura and Kishi did not describe the phakic status of their cohort, but $38 \%$ of our patients had previously undergone cataract extraction. Since their cohort was composed of volunteers and ours was a clinic population (many of whom had already undergone cataract surgery), this may have contributed to the higher separation rates seen in our study.

Itakura and Kishi used the presence of premacular bursae to rule out complete PVDs. They reported a high incidence of complete vitreous detachment $(80 \%)$ in patients over the age of 80 years but did not use B-scan ultrasonography to verify this number. Nonetheless, this is probably closer to the actual prevalence of complete PVD than we determined in our retrospective series. Our data prevent us from accurately determining the prevalence of PVD in the older age groups. But if we compare our 80- to 84-year group to the 50- to 54-year-old group and assume that the differences in partial vitreomacular separation represent progression to complete PVD, we can estimate that $>70 \%$ of our 80 - to 84-year-old patients had complete PVDs. This number is very close to that reported by Itakura and Kishi. ${ }^{13}$

A large prospective study of 2,198 subjects detected higher rates of partial vitreous separation. ${ }^{12}$ In the 50- to 59-, 60- to $69-, 70$ - to $79-$, and 80 - to 89 -year age groups, $\sim 85 \%$, $61 \%, 30 \%$, and $29 \%$ of patients had partial vitreous separation. Common to all three studies is the detection of higher rates of partial separation in the younger group (50-59 years), which decreases with advancing age. This is presumably because most of these eyes eventually progress to complete PVD.

The decreasing prevalence of partial separation with advancing age in our study was initially accompanied by an increase in the prevalence of complete PVD, from $1.7 \%$ in the $<50$-year group to $29.2 \%$ in the 70 - to 74 -year group. Counterintuitively, the prevalence of PVD then dropped to $22.6 \%$ in the 90- to 94-year group. Prospective studies of PVD have used both clinical examination and B-scan ultrasound to make this diagnosis. Many authors contend that ultrasound is necessary to correctly diagnose a PVD, since the predominantly transparent posterior hyaloid can be easily missed by clinical examination, thereby underestimating the true prevalence. ${ }^{11,22}$ Confirmatory ultrasound was not used in our study, and this probably affected the PVD prevalence rates we discovered, particularly for the 75+-year age groups. Younger patients generally have minimal cataracts and clear media, which makes for more accurate biomicroscopic evaluation of the vitreous. In advancing age groups, cataracts develop and vitreous syneresis progresses, thereby making accurate assessment of the posterior hyaloid more difficult. Additionally, the increasing prevalence of previous cataract surgery with accompanying capsular opacification and retained intracapsular lens material makes sensitive visualization of the posterior segment more difficult. We believe that these factors contributed to our underestimating the prevalence of PVD in the advancing age groups and may explain the decreasing prevalence of PVD in our study after the age of 74 years.

Our study was conducted over a 6-month period and is more representative of a snapshot of the posterior hyaloid in a clinic population rather than a longitudinal study. A trendline showed a decrease of $0.045 \mathrm{~mm}$ per year in the length of VMA throughout the cohort. Unfortunately, this is not a longitudinal study, and we cannot use this trend to accurately extrapolate the progression rate of posterior hyaloid separation. However, we can use the data from the different age groups to create a rough estimation for the fastest possible progression of posterior hyaloid separation. If we assume that the initial PVD prevalence in the 50- to 54-year age group is accurate and that all patients in the 85- to 89-year group have either partial or complete PVD, then $87 \%$ of patients would have developed PVDs during the 35-year aging period. Equally distributed, this means that a maximum of $2.5 \%$ of patients over the age of 50 years could develop a PVD each year.

The widespread adoption of SD-OCT together with the introduction of pharmacologic vitreolysis with ocriplasmin has increased interest in VRI abnormalities such as 
symptomatic VMT. The average age of patients treated with ocriplasmin is 68 years. ${ }^{23} \mathrm{We}$ found a partial vitreomacular separation prevalence of $44.7 \%$ in the 65 - to 69 -year group, which is well above that of the 80+-year age groups but significantly below the rate of the 50- to 54-year group. We believe that in patients who develop vitreoretinal separation at a younger age, adhesions are weaker between the posterior hyaloid and ILM, and therefore, they separate completely rather than developing symptomatic persistent traction. Patients who develop vitreomacular separation later in life may have greater adhesion strength. We propose that symptomatic VMT peaks in the seventh decade because a relatively high (though dwindling) number of patients have still not developed PVD and the remaining patients without PVD possess an increased adhesive strength. Our data also suggest a trend toward later vitreomacular separation in patients with diabetic retinopathy, consistent with the widely held belief that the posterior hyaloid in diabetic patients adheres more strongly to the ILM.

We found that the average length of attachment between the posterior hyaloid and ILM decreases with age. This is consistent with the observation that vitreous detachment begins in the peripheral macula and spreads slowly over a period of years. ${ }^{24}$ More elderly segments of the population have higher prevalences of complete PVDs, and those without PVDs have probably been experiencing progressive vitreoretinal separation for longer periods of time. Therefore, the smaller number of patients without PVD have shorter average lengths of persistent adhesion.

This study provides a cross-sectional view of vitreoretinal separation in a clinic population and suffers from several weaknesses. This retrospective study is plagued with all of the weaknesses associated with this methodology. Data regarding axial lengths are not available. Though we are confident about the accuracy of partial vitreoretinal separation as shown by SD-OCT, the prevalences of no vitreous separation and complete vitreous detachment in the older population groups are not accurate. B-scan ultrasonography would have improved the accuracy of the complete PVD data, but ultrasound is rarely used to evaluate vitreous detachment outside the confines of a prospective study.

\section{Conclusion}

In summary, we have found that the prevalence of partial vitreous separation peaks no later than the sixth decade and the average length of residual vitreoretinal adhesion follows a similar pattern. We suspect that patients with diabetic retinopathy may have stronger vitreoretinal adhesions, but larger studies are needed to confirm this. We believe that future prospective, population studies will better characterize the epidemiology and progression rates of vitreoretinal separation.

\section{Disclosure}

Michael W Stewart reports being a consultant for BoehringerIngelheim, receiving institutional research support from Allergan and Regeneron, being on the advisory boards for Allergan and Regeneron, and reports no other conflicts of interest in this work. Zahid Syed reports no conflicts of interest in this work.

\section{References}

1. Sebag J. Macromolecular structure of vitreous. Prog Polym Sci. 1998; 23:415-446.

2. De Smet MD, Gad Elkareem AM, Zwinderman AH. The vitreous, the retinal interface in ocular health and disease. Ophthalmologica. 2013; 230(4):165-178.

3. Bishop PN, Holmes DF, Kadler KE, McLeod D, Bos KJ. Age-related changes on the surface of vitreous collagen fibrils. Invest Ophthalmol Vis Sci. 2004;45(4):1041-1046.

4. Los LI, van der Worp RJ, van Luynn MJA, Hooymans JMM. Agerelated liquefaction of the human vitreous body: LM and TEM evaluation of the role of proteoglycans and collagen. Invest Ophthalmol Vis Sci. 2003;44(7):2828-2833.

5. Le Goff MM, Bishop PN. Adult vitreous structure and postnatal changes. Eye. 2008;22(10):1214-1222.

6. Balazs EA, Denlinger JL. Ageing changes in the vitreous. In: Dismukes K, Sekular R, editors. Ageing and Human Visual Function. New York, NY: Alan R Liss, Inc.; 1982:45-57.

7. Favre M, Goldmann H. Zur Genese der hinteren Glaskörperabhebung [On the genesis of posterior vitreous detachment]. Ophthalmologica. 1956;132:87-97. German.

8. Heller MD, Straatsma BR, Foos RY. Detachment of the posterior vitreous in phakic and aphakic eyes. Mod Probl Ophthalmol. 1972;10:23-36.

9. Sebag J. Vitreoschisis. Graefes Arch Clin Exp Ophthalmol. 2008;246(3): 329-332.

10. Geck U, Pustolla N, Baraki H, Atili A, Feltgen N, Hoerauf H. Posterior vitreous detachment following intravitreal drug injection. Graefes Arch Clin Exp Ophthalmol. 2013;251(7):1691-1695.

11. Kičová N, Bertelmann T, Irle S, Sekundo W, Mennel S. Evaluation of a posterior vitreous detachment: a comparison of biomicroscopy, B-scan ultrasonography and optical coherence tomography to surgical findings with chromodissection. Acta Ophthalmol. 2012;90(4): e264-e268.

12. Shao L, Xu L, You QS, et al. Prevalence and associations of incomplete posterior vitreous detachment in adult Chinese: the Beijing Eye Study. PLoS One. 2013;8(3):e58498.

13. Itakura $\mathrm{H}$, Kishi S. Evolution of vitreomacular detachment in healthy subjects. JAMA Ophthalmol. 2013;131(10):1348-1352.

14. Nasrallah FP, Jalkh AE, Van Coppenolle F, et al. The role of the vitreous in diabetic macular edema. Ophthalmology. 1988;95(10): 1335-1339.

15. Nasrallah FP, van de Velde F, Jalkh AE, Trempe CL, McMeel JW, Schepens CL. Importance of the vitreous in young diabetics with macular edema. Ophthalmology. 1989;96(10):1511-1516.

16. Weber-Krause B, Eckardt U. Häufigkeit einer hinteren Glaskörperabhebung bei Augen mit und ohne altersabhängiger Makuladegeneration Eine echographische Studie [Incidence of posterior vitreous detachment in eyes with and without age-related macular degeneration: an ultrasound study]. Ophthalmologe. 1996;93(6):660-665. German. 
17. Quaranta-El Maftouhi M, Mauget-Fayesse M. Anomalous vitreoretinal adhesions in patients with exudative age-related macular degeneration: an OCT study. Eur J Ophthalmol. 2006;16(1):134-137.

18. Öndes F, Yilmaz G, Acar MA, Ünlü N, Kocaoḡlan H, Arsan AK. Role of the vitreous in age-related macular degeneration. Jpn J Ophthalmol. 2000;44(1):91-93.

19. Krebs I, Brannath W, Glittenberg C, Zeiler F, Sebag J, Binder S. Posterior vitreomacular adhesion: a potential risk factor for exudative age-related macular degeneration? Am J Ophthalmol. 2007;144(5): 741-746.

20. Waldstein SM, Ritter M, Simader C, Mayr-Sponer U, Kundi M, Schmidt-Erfurth U. Impact of vitreomacular adhesion on ranibizumab mono- and combination therapy for neovascular age-related macular degeneration. Am J Ophthalmol. 2014;158(2):328-336.
21. Stalmans P, Benz MS, Gandorfer A, et al; MIVI-TRUST Study Group. Enzymatic vitreolysis with ocriplasmin for vitreomacular traction and macular holes. $N$ Engl J Med. 2012;367:606-615.

22. Sebag J. Imaging vitreous. Eye. 2002;16(4):429-439.

23. Xu LT, Punjabi OS, Shao J, et al. Frequency of vitreomacular interface disease in patients presenting to a tertiary care institution. Ophthalmic Surg Lasers Imaging Retina. 2014;45(6):517-520.

24. Johnson MW. Posterior vitreous detachment: evolution and complications of its early stages. Am J Ophthalmol. 2010;149(3):371-382.
Clinical Ophthalmology

\section{Publish your work in this journal}

Clinical Ophthalmology is an international, peer-reviewed journa covering all subspecialties within ophthalmology. Key topics include: Optometry; Visual science; Pharmacology and drug therapy in eye diseases; Basic Sciences; Primary and Secondary eye care; Patien Safety and Quality of Care Improvements. This journal is indexed on

Submit your manuscript here: http://www.dovepress.com/clinical-ophthalmology-journal

\section{Dovepress}

PubMed Central and CAS, and is the official journal of The Society of Clinical Ophthalmology (SCO). The manuscript management system is completely online and includes a very quick and fair peer-review system, which is all easy to use. Visit http://www.dovepress.com/ testimonials.php to read real quotes from published authors. 